\title{
Complex formation between 3,3'-diethylthiacarbo- cyanine iodide and DNA and its investigation in aqueous solution
}

\author{
M. Y. Anikovsky, A. S. Tatikolov, and V. A. Kuzmin \\ N. M. Emanuel Institute of Biochemical Physics, Russian Academy of Sciences, \\ 117977 Moscow, Russian Federation
}

\begin{abstract}
The binding of 3,3'-diethylthiacarbocyanine iodide (DTCC) with molecules of DNA was investigated by different photochemical methods. Absorption spectra were investigated under various concentration of DNA. Isosbestic points observed in these spectra are attributable to existence of two different complexes DTCC with DNA. Equilibrium constants of the formation of complexes I and II were determined $\left(K_{1} \approx 10^{6} \mathrm{M}^{-1}, K_{2} \approx 5 \times 10^{4} \mathrm{M}^{-1}\right.$ accordingly). Differential absorption spectra of two photoisomers of DTCC were obtained by flash photolysis method; it was found that the quantum yield of the short-lived photoisomer decreases and the quantum yield of the second long-lived photoisomer builds up with the increase in the DNA concentration. Kinetics of interaction between the triplet state of the dye and oxygen were investigated under various concentration of DNA. The growth of the quantum yield of fluorescence and intersystem crossing was observed with the increase in the DNA concentration.
\end{abstract}

\section{INTRODUCTION}

The interaction of dyes and other relative compounds with biomacromolecules forms the basis for a lot of photochemical processes. Practical importance of the process determining photodynamic therapy of cancer, medical treatment of a number of skin diseases proves the necessity of fundamental investigation in this area [1].

The most important processes are the reactions of the binding of different dyes with deoxyribonucleic acid (DNA) [2]. The DNA double strand defines special interaction of a number of organic molecules and leads to complex formation with high binding constants $\left(10^{4}\right.$ $10^{7} \mathrm{M}^{-1}$ ) [3]. Acridine orange, methylene blue, Bengal rose, ethydium bromide, thiazole orange are dyes, which have wide application in biochemistry and photobiology due to their capacity to form intermolecular complexes with deoxyribonucleic acid (DNA) under free energy changes of less than $10 \mathrm{kcal} / \mathrm{mol}(42 \mathrm{~kJ} / \mathrm{mol})$. These complexes are in the first place investigated in vitro. Nevertheless, there is good evidence that they are also present in biological systems where the nucleic acids exist in their natural states [3].

Investigations directed to the study of interaction of different types of the dyes with DNA have been carried out. The processes of interaction of polymethine dyes with DNA have been considered in a number of works [4-7]. However, the essential mechanisms of the binding of polymethine dyes with DNA stay uncertain.

\section{MATERIALS AND METHODS}

Measurements of the absorption spectra of the dye and its complexes were carried out on a "Shimadzu UV-1601 PC" spectrophotometer in a cell with the optical path length of $1 \mathrm{~cm}$. Flash photolysis equipment with flash energy $50 \mathrm{~J}$ and flash duration at half max- imum of $7 \mu \mathrm{s}$ [8] and dye laser flash photolysis equipment $\left(\lambda_{\text {gen }}=540 \mathrm{~nm}\right.$, excitation with a nitrogen laser, $\lambda_{\mathrm{ex}}=337 \mathrm{~nm}, W=0.8 \mathrm{~mJ}, \tau_{1 / 2} \approx 1 \mathrm{~ns}$ ) [9] were used for the study of the triplet state of DTCC, trans-cisphotoisomerization, back thermal isomerization, determination of the quenching rate constant of the dye triplet state by oxygen. Measurements of fluorescence quantum yields of the dye were carried out on an "Amico-Bowman" spectrofluorimeter with an R136 photomultiplier by the comparison with the standard, DTCC in methanol (with fluorescence quantum yield of $5 \%[10,11])$. In this work, calf thymus DNA (Aldrich) purified by dialysis was used [12]. Concentration of DNA was determined by the use of extinction coefficient $\varepsilon=6700 \mathrm{M}^{-1} \mathrm{~cm}^{-1}$, which corresponds to the absorption of a base pair [13]. Phosphate buffer $\mathrm{pH} 7$ with concentration $20 \mu \mathrm{M}$ was used as a solvent.

\section{RESULTS AND DISCUSSION}

This report deals with the binding of $3,3^{\prime}$ diethylthiacarbocyanine iodide with DNA in aqueous solution.

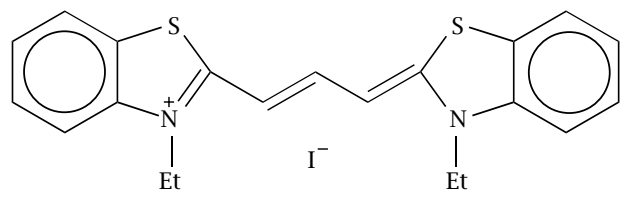

This dye was chosen in this work because it has a high quantum yield of photoisomerization, low triplet quantum yield at direct photoexcitation $\left(\Phi_{\text {isc }}^{\text {trans }}<0.001\right)[14]$ and low fluorescence quantum yield (5\% in methanol). The fluorescence quantum yield of DTCC in aqueous solution (phosphate buffer, $\mathrm{pH}$ 7) without DNA was determined to be $2.6 \%$. 
Absorption spectra of the dye were recorded at constant concentration of the dye $(\mathrm{OD}=0.36)$ and different concentrations of DNA $\left(c_{\mathrm{DNA}}=0-4.63 \times 10^{-4} \mathrm{M}\right)$.

Isosbestic points observed in the absorption spectra in the areas of low DNA concentrations $\left(c_{\mathrm{DNA}}=(2-\right.$ $\left.5) \times 10^{-5} \mathrm{M}\right)$ and high DNA concentrations $\left(c_{\mathrm{DNA}}=(2.5-\right.$ $4.5) \times 10^{-4} \mathrm{M}$ ) (Figure 1) are attributable to formation of two different dye-DNA complexes according to the following scheme:

$$
\text { dye }+ \text { DNA } \rightleftarrows \text { complex I }
$$

complex I+DNA $\rightleftarrows$ complex II
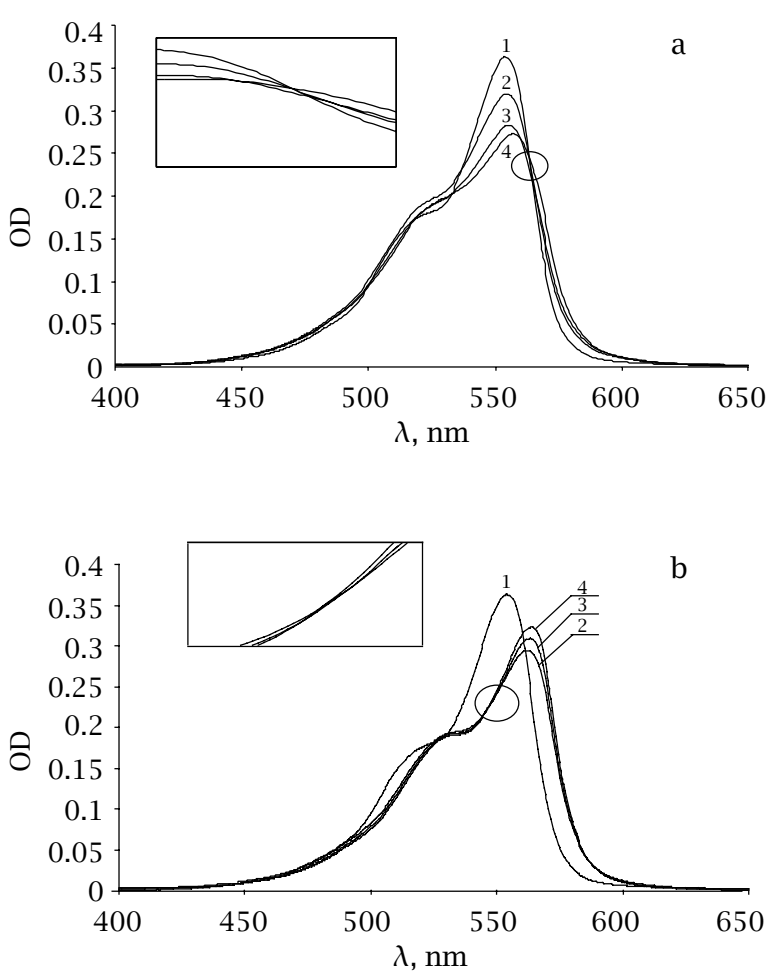

Figure 1. Absorption spectra of 3,3'-diethylethiacarbocyanine iodide (a) at low DNA concentrations: $c_{\mathrm{DNA}}=0(1)$, $2.3 \times 10^{-5} M(2), 4.9 \times 10^{-5} M(3), 9.4 \times 10^{-5} M(4)$; (b) at high DNA concentrations: $c_{\mathrm{DNA}}=0(1), 2.8 \times 10^{-4} M(2)$, $3.8 \times 10^{-4} M(3), 4.6 \times 10^{-4} M(4)$.

In view of the fact that the appreciable displacement of the absorption spectrum of the dye to longer wavelengths is observed (about $10 \mathrm{~nm}$ ) at high DNA concentration, it is believed that a dye molecule intercalates between two base pairs of a DNA molecule to which it is bound [3].

Photochemical characteristics of the dye-DNA complexes were investigated by flash photolysis method. In this case, the strong influence of DNA on the processes in the dye molecule has been found.

Hand in hand with fluorescence, energy degradation of the excited singlet state of polymethine dye molecules in aqueous solutions happens as a result of intersystem crossing into the triplet state and trans-cis photoisomerization [15]. It is common knowledge that trans-cis photoisomerization of carbocyanine dyes happens through the excited singlet state [16].

The process of trans-cis photoisomerization competes with the fluorescence and provides low quantum yield of intersystem crossing into the triplet state.

Upon photoexcitation of DTCC in polar solvents (ethanol, dimethylsulfoxide, acetonitrile), the contribution of fluorescence and intersystem crossing in deactivation of excited singlet molecules is low. The main process of nonradiative deactivation is internal conversion according to the mechanism of photoisomerization of the dye in the singlet excited state. Direct photoexcitation leads to the formation of the short-lived photoisomer around the $2-8$ bond $[17,18]$.

$$
\begin{gathered}
\operatorname{trans} S_{0}+h v \rightarrow S^{*} \rightarrow \operatorname{cis} S_{0} \\
\operatorname{cis} S_{0} \longrightarrow \operatorname{trans} S_{0} \quad\left(k_{1}=7 \times 10^{2} \mathrm{~s}^{-1}\right)
\end{gathered}
$$

Upon flash photolysis excitation of the dye-DNA complexes, the formation of two photoisomers is observed: the short- and long-lived ones, which differential absorption spectra are shifted to shorter wavelength (Figure 2). An increase in DNA concentration leads to the decrease in the quantum yield of the short-lived photoisomer and to the growth of the quantum yield of the long-lived photoisomer.
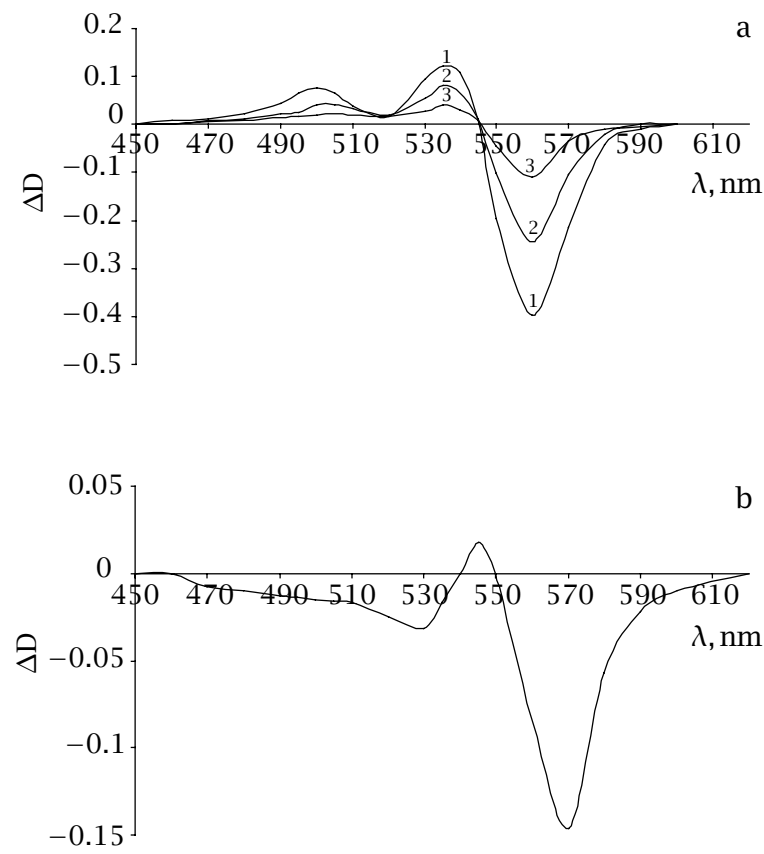

Figure 2. Differential absorption spectra of 3,3'-diethylethiacarbocyanine iodide obtained by flash photolysis (a) short-lived photoisomer at $30 \mu \mathrm{s}$ after the flash at different DNA concentrations: $c_{\text {DNA }}=0(1), 4 \times 10^{-5} M(2), 4 \times 10^{-4}$ $M(3)$; (b) long-lived photoisomer at $700 \mu$ s after the flash at DNA concentration $c_{\mathrm{DNA}}=4 \times 10^{-4} \mathrm{M}$.

For symmetrical carbocyanines, it is possible the formation of only two isomers: around the 2-8 and 8- 
9 bonds. With no DNA, only short-lived photoisomer around the 2-8 bond is observed. The long-lived photoisomer detected only in the presence of DNA is attributable to the rotation around the 8-9 bond.

An increase in DNA concentration also leads to the growth of the triplet state quantum yield. The direct population of the triplet levels of polymethine dyes takes place under conditions, which hinder trans-cis photoisomerization [19]. By this means, it's possible to explain the drop of the photoisomerization quantum yield and the growth of the triplet state quantum yield by an increase in rigidity of the dye molecules, which are bound to DNA.

The quenching rate constant of the triplet state of DTCC by oxygen in the presence of DNA is of the order of $3 \times 10^{8} \mathrm{M}^{-1} \mathrm{~s}^{-1}$ (Figure 3). This value is much less than the diffusion-controlled rate constant for triplet state quenching by oxygen which was determined to be $1.2 \times 10^{9} \mathrm{M}^{-1} \mathrm{~s}^{-1}$. It seems reasonable to say that, because of intercalation of the dye molecules into DNA, the access of oxygen to the molecules of DTCC becomes difficult, which results in decrease of the quenching rate constant.
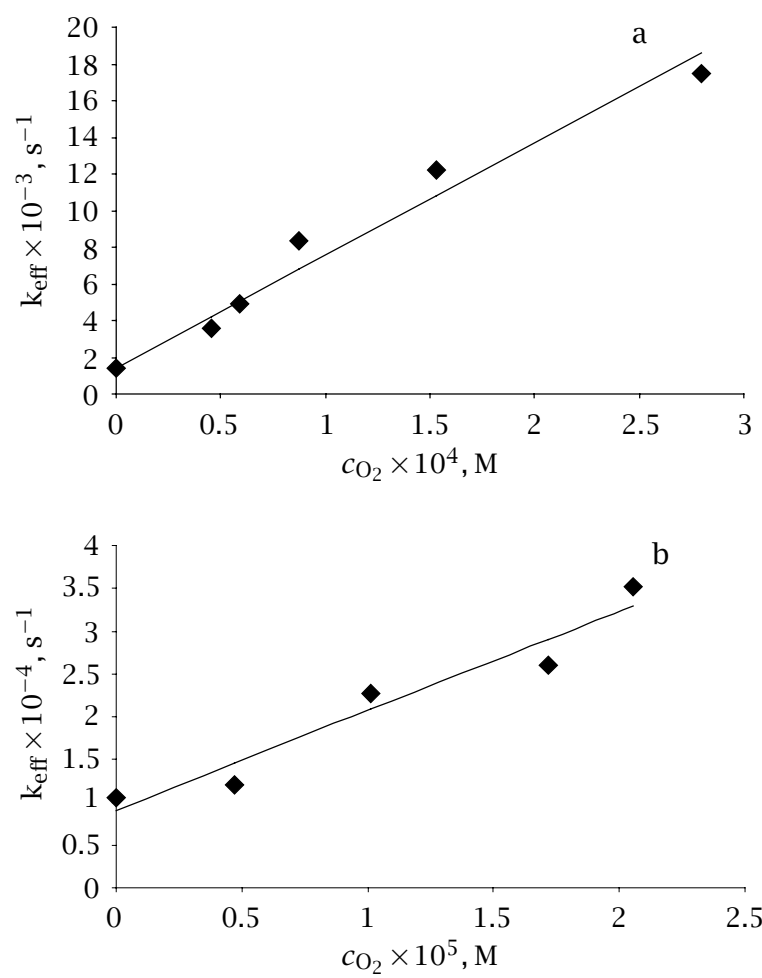

Figure 3. Dependence of the rate constant for the decay of the triplet state of DTCC on oxygen concentration: (a) in the absence of DNA; (b) in the presence of DNA (the triplet state of the dye was obtained by triplet energy transfer from anthracene).

The influence of DNA on the photochemical processes in the dye molecules also appears in the growth of the fluorescence quantum yield of DTCC with increasing DNA concentration (Figure 4). It is common knowledge that the processes of trans-cis photoisomer- ization and fluorescence are competitive. Steric hindrances resulting from the binding of the dye with DNA prevent the process of trans-cis photoisomerization, which results in the growth of fluorescence.

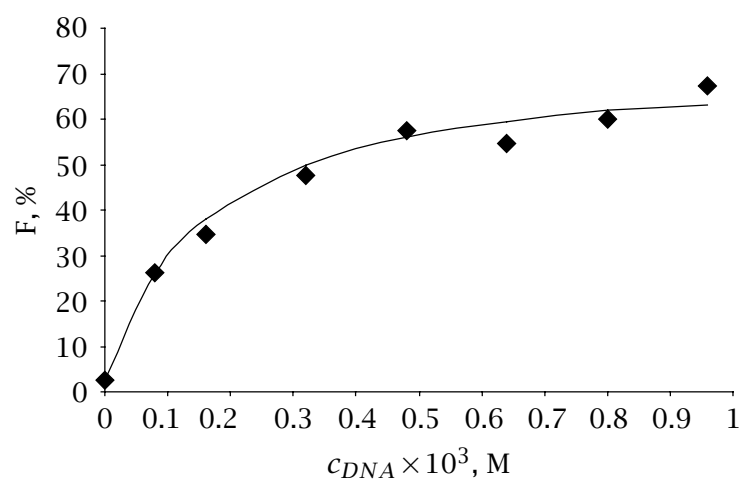

Figure 4. Dependence of the fluorescence quantum yield of DTCC on DNA concentration.

A reliable determination of the complex stoichiometry was provided by the method based on the dependence of fluorescence intensity $\Delta F\left(\Delta F=F-F_{0}\right.$, where $F$ and $F_{0}$ are fluorescence intensities in the presence and absence of DNA accordingly) on the composition of the system dye-DNA [20]. The dye and DNA concentrations were changed in such a way that their total concentration remained invariable $\left(c_{\text {dye }}+c_{\mathrm{DNA}}=\right.$ const $=$ $\left.7 \times 10^{-6} \mathrm{M}\right)$. Dependence of changes in fluorescence on $r\left(r=c_{\text {dye }} /\left(c_{\text {dye }}+c_{\text {DNA }}\right)\right)$ is given in Figure 5.

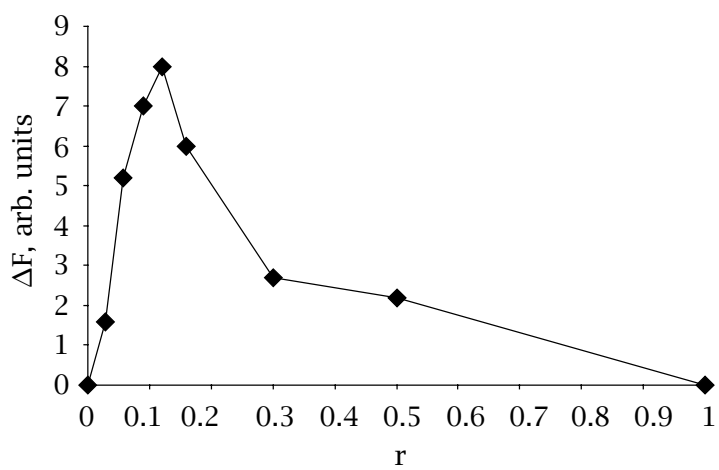

Figure 5. Dependence of the fluorescence intensity of DTCC on the composition of the system dye-DNA (parameter $r$ ).

Maximum absolute concentration of the dye-DNA complex is reached for $r=(n+1)^{-1}$, where $n$ is a number of base pairs per one dye molecule intercalated into DNA. Maximum fluorescence growth is also observed at $r=(n+1)^{-1}$ [20]. From Figure 5 it can be seen that maximum $\Delta F$ is observed at $r \approx 0.09\left(c_{\mathrm{DNA}}=6.2 \times 10^{-6} \mathrm{M}\right)$, which corresponds to $n \approx 10$. By this means it is believed that in complex I one dye molecule corresponds to ten base pairs, that is to one turn of DNA helix. DNA concentration at which maximum on the curve in Figure 5 is reached corresponds to the formation of complex I. It is possible to suppose that a dye molecule in- 
tercalates between base pairs by one of terminal heterocycles upon the formation of this complex. Complex I converts into complex II with increasing DNA concentration. There are good reasons for believing that the formation of complex II occurs from complex I via intercalation of another free heterocyclic end of a dye molecule between base pairs of DNA helix. The equilibrium constant of the formation of complex I was estimated from the fluorescence growth with the growth of DNA concentration up to $c_{\mathrm{DNA}}=10^{-4} \mathrm{M}$ (initial part of the curve in Figure 5):

$$
\Delta F=k_{0} c_{\text {dye }}{ }^{*}+k_{1} c_{\text {complexI }}-k_{0} c_{\text {dye }},
$$

where

$c_{\text {dye }}{ }^{*}$ is the concentration of non-complexed dye,

$c_{\text {complex I }}$ is the concentration of complex I per one turn of DNA helix,

$k_{0}$ is the factor correlating the dye concentration with the fluorescence intensity:

$$
k_{0}=\frac{F_{0}}{c_{\text {dye }}}
$$

$k_{1}$ is the factor correlating the concentration of complex I with the fluorescence intensity:

$$
k_{1}=\frac{F}{c_{\text {complexI }}} \text {. }
$$

Considering that at $c_{\mathrm{DNA}}=1.6 \times 10^{-4} \mathrm{M}$ (Figure 5) all dye molecules are in complex I, it is possible to determine $k_{1}$ :

$$
k_{1}=\frac{F}{c_{\text {dye }}}
$$

where $F$ is the fluorescence intensity at $c_{\mathrm{DNA}}=1.6 \times$ $10^{-4} \mathrm{M}$.

It was determined that one molecule of the dye corresponds to one turn of DNA helix upon formation of complex I; therefore, the equilibrium constant of the formation of complex I $\left(K_{1}\right)$ should be calculated with DNA concentration corresponding to one turn of DNA helix (10 base pairs) rather than one base pair:

$$
K_{1}=\frac{c_{\text {complexI }}}{\left(c_{\text {dye }}{ }^{*} c_{\text {DNA }} *^{\prime}\right)},
$$

where $c_{\mathrm{DNA}} *^{\prime}$ is the concentration of non-complexed DNA calculated to one turn of DNA helix.

Based on

$$
\begin{gathered}
c_{\text {dye }}=c_{\text {dye }}{ }^{*}+c_{\text {complexI }}, \\
c_{\text {DNA }}{ }^{\prime}=c_{\text {DNA }}{ }^{\prime}+c_{\text {complexI }},
\end{gathered}
$$

where $c_{\mathrm{DNA}}$ is the DNA concentration calculated to one turn of helix, from equations (1), (2), (3), and (4) the expression for the equilibrium constant of the formation of complex I was determined:

$$
K_{1}=\frac{\frac{\Delta F}{(\beta-\alpha)}}{\left\{c_{\text {dye }}-\frac{\Delta F}{\beta-\alpha}\right\}\left\{c_{\text {DNA }^{\prime}}-\frac{\Delta F}{\beta-\alpha}\right\}} .
$$

The equilibrium constant of the formation of complex I was found to be $K_{1} \approx 10^{6} \mathrm{M}^{-1}$.
It can be seen from the position of the second isosbestic point in the absorption spectra of the dye in the presence of DNA (Figure 1b) that the formation of complex II is related to the range of DNA concentrations $(2.5-5) \times 10^{-4} \mathrm{M}$. Then the expression for fluorescence intensity at DNA concentration $c_{\mathrm{DNA}}=4.8 \times 10^{-4} \mathrm{M}$ can be written:

$$
F=k_{2} c_{2}+k_{1} c_{1},
$$

where $k_{2}$ is the factor correlating the concentration of complex II with the fluorescence intensity:

$$
k_{2}=\frac{F}{c_{\text {complex II }}} .
$$

At DNA concentration $c_{\mathrm{DNA}}=9.6 \times 10^{-4} \mathrm{M}$ (Figure 4) all dye molecules are in complex II, therefore, $k_{2}$ may be determined as

$$
k_{2}=\frac{F}{c_{\text {dye }}},
$$

where $F$ is the fluorescence intensity at DNA concentration $c_{\text {DNA }}=9.6 \times 10^{-4} \mathrm{M}$.

The equilibrium constant of the formation of complex II may be written as:

$$
K_{2}=\frac{c_{\text {complexII }}}{c_{\text {complexI }} c_{\mathrm{DNA}} *^{\prime}},
$$

where $c_{\text {complex II }}$ is the concentration of complex II calculated to the turn of helix.

Considering that at the DNA concentration in the range $c_{\mathrm{DNA}} \approx 1.5 \times 10^{-4}-5 \times 10^{-4} \mathrm{M}$ all dye molecules are in complexes I and II it is possible to write:

$$
\begin{aligned}
c_{\text {dye }} & =c_{\text {complexI }}+c_{\text {complex II }}, \\
c_{\text {DNA }}{ }^{\prime} & =c_{\text {DNA }}{ }^{\prime}+2 c_{\text {complex II }}+c_{\text {complexI }} .
\end{aligned}
$$

From equations (5), (6), (7), and (8) the expression for the equilibrium constant of the formation of complex II was determined:

$$
K_{2}=\frac{\frac{F-\beta c_{\text {dye }}}{\gamma-\beta}}{\left\{c_{\text {dye }}-\frac{F-\beta c_{\text {dye }}}{\gamma-\beta}\right\}\left\{c_{\text {DNA }}{ }^{\prime}-\frac{F-\beta c_{\text {dye }}}{\gamma-\beta} c_{\text {dye }}\right\}} .
$$

The equilibrium constant of the formation of complex II is $K_{2}=5 \times 10^{4} \mathrm{M}^{-1}$.

It should be pointed out that the photostability of DTCC in the complexes with DNA is higher than in the absence of DNA. The steric hindrances upon complex formation leads to the reduction in interaction efficiency of the dye excited state with oxygen and other impurities resulting in the growth of photochemical stability of the dye. 


\section{REFERENCES}

[1] G. Zhizhina, S. Moskalenko, V. Sinyak, Yu. Shekun, and M. Yakshin, Biophysics 35 (1990), 47.

[2] H. Rye, S. Yue, D. Wemmer, M. Quesada, R. Haugland, R. Mathies, and A. Glazer, Nucl. Acids Research 20 (1992), 2803.

[3] G. Lober, Journal of Luminescence 22 (1981), 221.

[4] S. Yarmoluk, V. Kovalska, T. Smirnova, M. Shandura, Y. Kovtun, and G. Matsuka, Biopolymers and Cell 12 (1996), 74.

[5] T. Netzel, K. Nafisi, M. Zhao, J. Lenhard, and I. Johnson, J. Phys. Chem. 99 (1995), 17936.

[6] J. Jacobsen, J. Pedersen, L. Hansen, and D. Wemmer, Nucl. Acids Research 23 (1995), 753.

[7] H. Rye and A. Glazer, Nucl. Acids Research 23 (1995), 1215.

[8] Yu. Borisevich, A. Tatikolov, and V. Kuzmin, High En. Chem. 5 (1978), 474.

[9] P. Levin and V. Kuzmin, Russ. Chem. Bull., Div. Chem. Sci. (1987), 1901.

[10] N. Roth and A. Craig, J. Phys. Chem. 78 (1974), 1154.
[11] V. Mostovnikov, A. Rubinov, M. Al'perovich, V. Avdeeva, I. Levkoev, and M. Loiko, Journal of applied spectr. 20 (1974), 42.

[12] G. Kelly and T. Kurucsev, Biopolymers 15 (1976), 1481.

[13] V. Shafirovich, P. Levin, V. Kuzmin, T. Thorgeirsson, D. Kliger, and N. Geacintov, The Journal of the American Chemical Society 116 (1994), 65.

[14] Yu. Lifanov, V. Kuzmin, A. Chibisov, I. Levkoev, and A. Karyakin, Journal of Applied Spectr. 20 (1974).

[15] V. Kuzmin, Uspekhi nauchnoi photografii (rus. Progress in Photographic Science), 12 (1984), 90.

[16] A. Chibisov, V. Kuzmin, G. Roitman, I. Levkoev, and A. Karyakin, Russ. Chem. Bull., Div. Phys. Sci. 34 (1970), 1288.

[17] I. Baraldi, A. Carnevali, F. Momicchioli, G. Ponterini, and G. Berthier, Gazzetta Chimica Italiana 126 (1996), 211.

[18] V. Kuzmin, A. Vinogradov, M. Al'perovich, and I. Levkoev, Docl. Phys. Chem. 224 (1975), 139.

[19] Yu. Lifanov, V. Kuzmin, A. Chibisov, and I. Levkoev, High En. Chem. 7 (1973), 1973.

[20] Y. Loukas, J. Phys. Chem. B 101 (1997), 4863. 


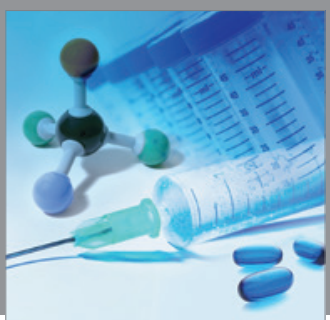

International Journal of

Medicinal Chemistry

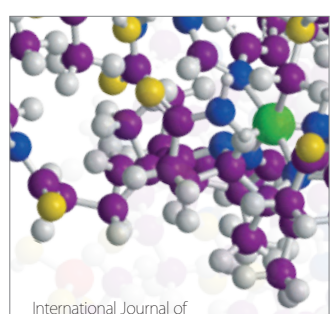

Carbohydrate Chemistry

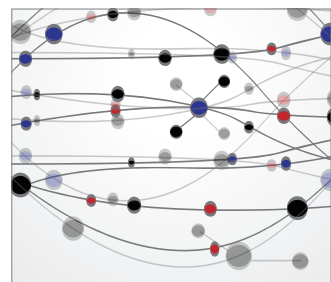

The Scientific World Journal
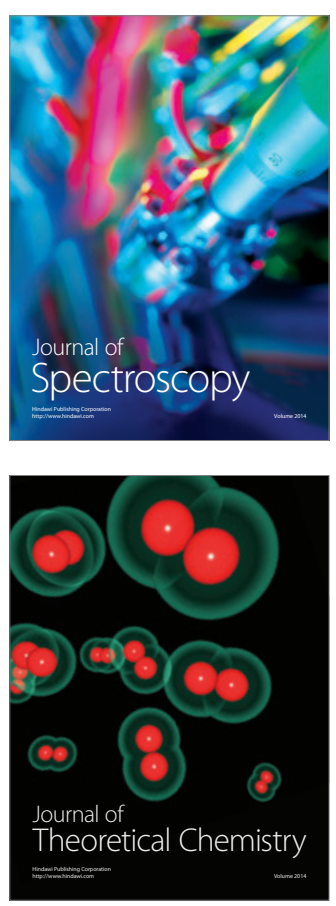
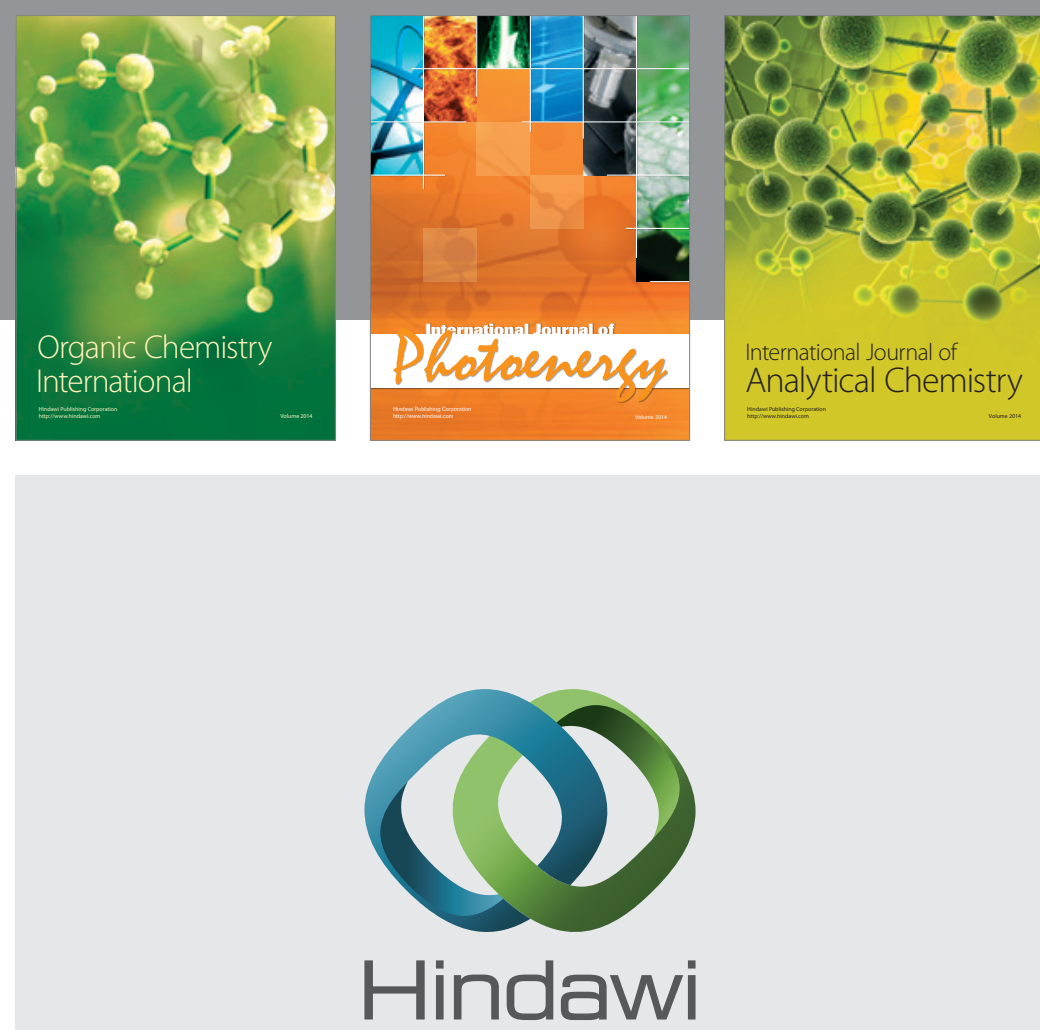

Submit your manuscripts at

http://www.hindawi.com
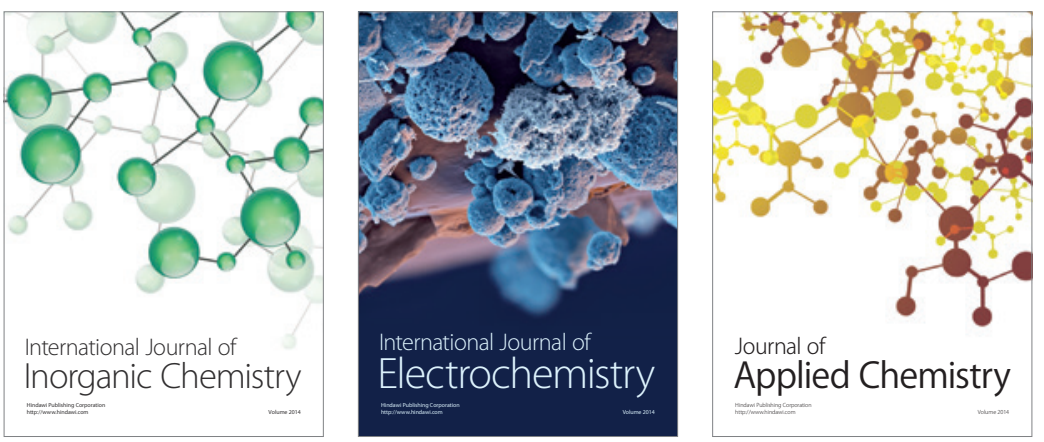

Journal of

Applied Chemistry
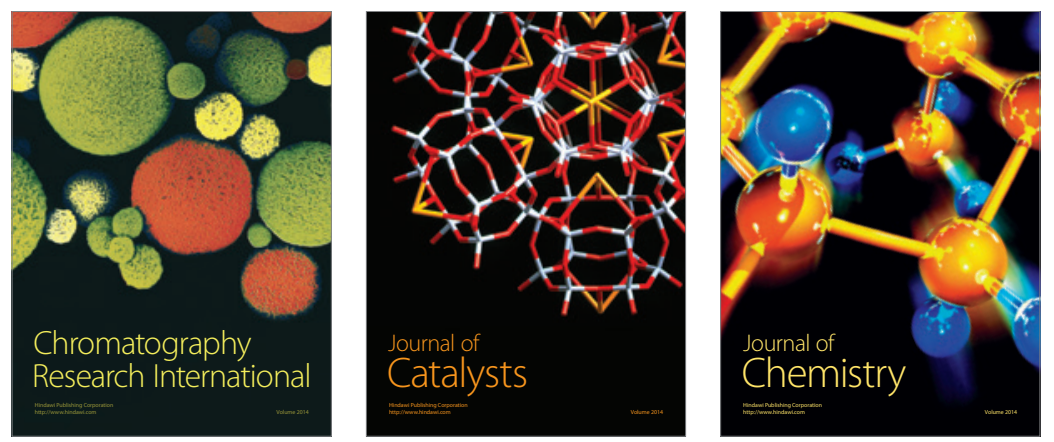
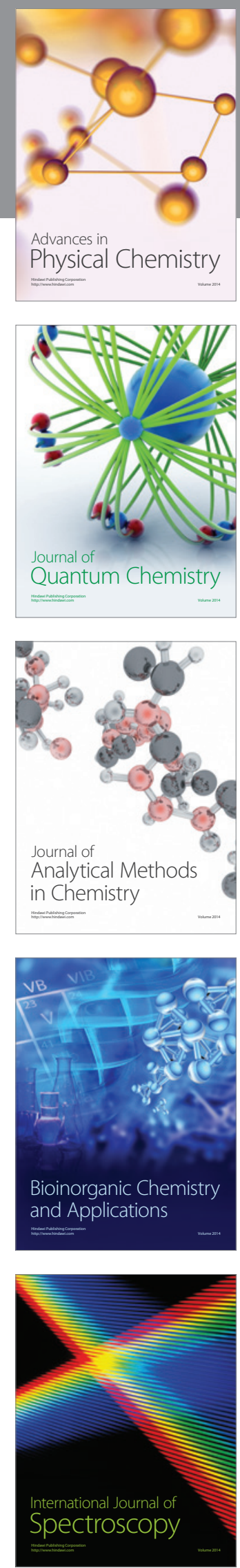